\title{
Nitric oxide participates in the regulation of ascorbate-glutathione cycle and water physiological characteristics of Arabidopsis thaliana by NaHS
}

\author{
C.J. SHAN ${ }^{* * *,+}$, Y.Y. JIN*, Y. ZHOU ${ }^{*, * *}$, and H. LI"** \\ Henan Institute of Science and Technology, Xinxiang 453003, China* \\ Collaborative Innovation Center of Modern Biological Breeding, Henan Province, Xinxiang 453003, China** \\ School of Life Sciences, Henan University, Kaifeng 475004, China ${ }^{* * *}$
}

\begin{abstract}
We investigated the role of nitric oxide (NO) in the regulation of ascorbate-glutathione (AsA-GSH) cycle and water physiological characteristics of Arabidopsis thaliana by sodium hydrosulfide (NaHS). NaHS markedly increased the contents of $\mathrm{H}_{2} \mathrm{~S}$, NO, chlorophyll (Chl), and carotenoids, the activity of AsA-GSH cycle, ascorbate/dehydroascorbate ratio, net photosynthetic rate, $\mathrm{Chl}$ fluorescence parameters, transpiration rate, stomatal conductance, and relative water content in leaves and the biomass of wild-type Arabidopsis. However, NaHS markedly decreased malondialdehyde content and electrolytic leakage. Except $\mathrm{H}_{2} \mathrm{~S}$, above NaHS-induced promotions were suppressed by nitrate reductase (NR) inhibitor sodium azide $\left(\mathrm{NaN}_{3}\right)$. Application of sodium nitroprusside (SNP) to $\left(\mathrm{NaN}_{3}+\mathrm{NaHS}\right)$-treated wild type Arabidopsis $\left(\mathrm{NaN}_{3}+\mathrm{SNP}+\mathrm{NaHS}\right)$ reversed above effects of $\mathrm{NaN}_{3}+\mathrm{NaHS}$. However, $\mathrm{NaN}_{3}+\mathrm{NaHS}$ and $\mathrm{NaN}_{3}+\mathrm{SNP}+\mathrm{NaHS}$ had no significant effects on $\mathrm{H}_{2} \mathrm{~S}$ content. Meanwhile, we proved above results by using NO-associated NR gene mutant nia 1 , nia2 . Above results suggested that NO participated in the regulation of AsA-GSH cycle and water physiological characteristics of Arabidopsis by NaHS.
\end{abstract}

Additional key words: donor; gas exchange; Halliwell-Asada pathway; hydrogen sulfide; nitric oxide; nitrate reductase gene mutant.

\section{Introduction}

Ascorbate (AsA) is an important metabolite, which plays various physiological functions in plants (Horemans et al. 2000). First, AsA is an important antioxidant in cells and helps other antioxidants fulfil their functions (Horemans et al. 2000, Shan et al. 2018). Second, AsA regulates the division, expansion, and elongation of cells (Potters et al. 2002). Third, AsA regulates plant defense and survival by modulating the expression of defense genes and photosynthetic genes, etc. (Kiddle et al. 2003). Finally, AsA regulates the redox equilibrium of plants by modulating the redox state (Shan et al. 2018). Ascorbateglutathione (AsA-GSH) cycle (Halliwell-Asada pathway) has important roles in maintaining AsA content and the redox equilibrium in plants (Avashthi et al. 2018). In this cycle, ascorbate peroxidase (APX) can remove
$\mathrm{H}_{2} \mathrm{O}_{2}$. Monodehydroascorbate reductase (MDHAR) and dehydroascorbate reductase (DHAR) can realize the regeneration of AsA. Glutathione reductase (GR) is responsible for the regeneration of GSH (Shan et al. 2015). Thus, AsA-GSH cycle has the important role in balancing the redox state of ascorbate in plants, which further regulates plant growth and development. Therefore, we can regulate the redox state of ascorbate through AsAGSH cycle by using exogenous substances.

Hydrogen sulfide $\left(\mathrm{H}_{2} \mathrm{~S}\right)$ is a key gas signal molecule in plants. Increasing evidence shows that $\mathrm{H}_{2} \mathrm{~S}$ fulfils important roles in regulating plant growth, development, and other physiological processes (Li et al. 2017, Kaya and Ashraf 2019, Mei et al. 2019). Nitric oxide (NO) is another key gas signal molecule in plants (Hasanuzzaman et al. 2018, Recalde et al. 2018, Okant and Kaya 2019). Increasing evidence also showed that NO is involved in

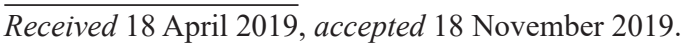

${ }^{+}$Corresponding author; e-mail: shanchangjuan1978@,163.com

Abbreviations: APX - ascorbate peroxidase; AsA - ascorbate; AsA/DHA - the ratio of ascorbate to dehydroascorbate; AsA-GSH ascorbate-glutathione; Car - carotenoids; Chl - chlorophyll; DHAR - dehydroascorbate reductase; $E$ - transpiration rate; EL - electrolyte leakage; $F_{v} / F_{m}$ - maximum photochemical efficiency of PSII; $g_{s}$ - stomatal conductance; GR - glutathione reductase; MDA - malondialdehyde; MDHAR - monodehydroascorbate reductase; NR - nitrate reductase; $P_{\mathrm{N}}$ - net photosynthetic rate; $\Phi_{\mathrm{PSII}}$ - effective quantum yield of PSII; $\mathrm{q}_{\mathrm{N}}$ - nonphotochemical quenching; $\mathrm{q}_{\mathrm{P}}$ - photochemical quenching; RWC - relative water content; SNP - sodium nitroprusside.

Acknowledgements: This study was supported by Project of Supporting Young Backbone Teachers of Colleges and Universities in Henan province (2016GGJS-108), National Fund Cultivation Project of Henan Institute of Science and Technology (2018GJ05), the Scientific Research Foundation for Postdoctors of Henan Province (2015104), Basic and Frontier Technology Research Programs from the Department of Science and Technology of Henan Province (152300410093), and The Postgraduate Education Reform and Quality Improvement Project of Henan Province (Yu degree [2018] No. 23).
} 
the regulation of plant growth, development, and other physiological processes, such as root growth and stomatal movement (Hao et al. 2010, Wang et al. 2010, Zhao et al. 2010, Sun et al. 2017). Many studies showed that AsAGSH cycle regulates the redox state of ascorbate (Shan et al. 2015, Avashthi et al. 2018). However, the signal regulation mechanism of AsA-GSH cycle is still unclear. Our previous study showed that $\mathrm{H}_{2} \mathrm{~S}$ regulated the redox state of ascorbate through AsA-GSH cycle in Arabidopsis thaliana (Shan et al. 2018). Our previous studies also showed that NO regulated the redox state of ascorbate through AsA-GSH cycle in maize and Agropyron cristatum (Shan et al. 2012, Shan and Sun 2018). Besides, our previous study showed that $\mathrm{H}_{2} \mathrm{~S}$ donor sodium hydrosulfide (NaHS) regulated the redox state of ascorbate through AsA-GSH cycle in wheat (Shan et al. 2011). However, whether signal molecule NO can participate in the regulation of AsA-GSH cycle in A. thaliana by NaHS is still unclear. Thus, it is very important to elucidate the role of NO in NaHS-signaling the redox state of ascorbate through AsA-GSH cycle in $A$. thaliana.

It has been documented that NaHS improved the growth of rice seedlings and submerged macrophytes by regulating water physiological characteristics, including photosynthesis, chlorophyll (Chl) fluorescence, gas exchange, etc. (Duan et al. 2015, Parveen et al. 2017). NO had positive effects on photosynthesis, Chl fluorescence, and gas exchange of Crambe abysinica and tomato (Ahmad et al. 2018, Batista et al. 2018). However, whether signal molecule NO can participate in the regulation of above water physiological characteristics in $A$. thaliana by $\mathrm{NaHS}$ is still unclear. Thus, it is very important to elucidate the role of NO in the regulation of photosynthesis, Chl fluorescence, and gas exchange of $A$. thaliana.

In this study, we investigated the contents of $\mathrm{H}_{2} \mathrm{~S}, \mathrm{NO}$, $\mathrm{Chl}$, and carotenoids (Car), activities of four enzymes in the AsA-GSH cycle, the ratio of ascorbate to dehydroascorbate (AsA/DHA), leaf relative water content (RWC) and plant biomass, net photosynthetic rate $\left(P_{\mathrm{N}}\right)$, transpiration rate $(E)$, stomatal conductance $\left(g_{s}\right)$, and Chl fluorescence parameters, such as maximum photochemical efficiency of PSII $\left(\mathrm{F}_{\mathrm{v}} / \mathrm{F}_{\mathrm{m}}\right)$, photochemical quenching $\left(\mathrm{q}_{\mathrm{P}}\right)$, nonphotochemical quenching $\left(\mathrm{q}_{\mathrm{N}}\right)$, and quantum efficiency of PSII photochemistry $\left(\Phi_{\mathrm{PSII}}\right)$, in wild-type $A$. thaliana and NO-associated mutant of nitrate reductase (NR) gene (nia1,nia2). The scope and need of this study was to elucidate the role of NO in the signal process of $\mathrm{NaHS}$ in regulating AsA-GSH cycle, photosynthesis, Chl fluorescence and gas exchange of $A$. thaliana, which could provide new knowledge on the action mechanism of NaHS in plants.

\section{Materials and methods}

Plant culture and treatment: Seeds of wild-type Arabidopsis and mutant nia1, nia2 were bought from Arabidopsis Biological Resource Center (ABRC) in USA. The ecotype of Arabidopsis is Col-0. Ten-day-old seedlings were transferred to half-strength Hoagland's solution. Then, 28-d-old seedlings with uniform height and growth status were selected for our experiments. To study the effect of NaHS, 28-d-old seedlings were transferred to halfstrength Hoagland's solution containing $0.2 \mathrm{mM} \mathrm{NaHS}$ (Sigma-Aldrich, USA) for $7 \mathrm{~d}$. To study the effect of NR inhibitor sodium azide $\left(\mathrm{NaN}_{3}\right)$, plants were pretreated with $0.1 \mathrm{mM} \mathrm{NaN}_{3}$ for $8 \mathrm{~h}$ and then exposed to $0.2 \mathrm{mM} \mathrm{NaHS}$ for $7 \mathrm{~d}$. To investigate whether the effect of $\mathrm{NaN}_{3}$ can be reversed by exogenous $\mathrm{NO}$, the plants were pretreated with $0.1 \mathrm{mM} \mathrm{NaN}_{3}$ for $8 \mathrm{~h}$ and then treated by $100 \mu \mathrm{M}$ NO donor, sodium nitroprusside (SNP), plus $0.2 \mathrm{mM}$ $\mathrm{NaHS}$ for $7 \mathrm{~d}$. Control plants were treated by half-strength Hoagland's solution alone. The solutions of SNP, $\mathrm{NaN}_{3}$, and NaHS were prepared by adding these compounds into half-strength Hoagland's solution, respectively. To further prove the role of NO in the regulation of AsA-GSH cycle, photosynthesis, Chl fluorescence, and gas exchange of A. thaliana by NaHS, we investigated the effects of SNP and NaHS on corresponding indicators in NO-associated mutant nia1,nia2. The plants of mutant nia1,nia2 were exposed to $0.2 \mathrm{mM} \mathrm{NaHS}$ or $100 \mu \mathrm{M} \mathrm{SNP}+0.2 \mathrm{mM} \mathrm{NaHS}$ for $7 \mathrm{~d}$. In each treatment, the number of repetitions was five. After $2 \mathrm{~d}$ of treatment, the top fully expanded leaves of seedlings were collected and frozen in liquid nitrogen, and then kept at $-80^{\circ} \mathrm{C}$ until analyses. All the experiments were operated in a greenhouse. The greenhouse conditions were as follows: the temperature ranged from about $22 \pm 2^{\circ} \mathrm{C}$, the relative humidity was $70 \%$, and the photoperiod was $16 \mathrm{~h}$ with PPFD of $120 \mu \mathrm{mol}$ (photon) $\mathrm{m}^{-2} \mathrm{~s}^{-1}$. After treatment for $7 \mathrm{~d}$, plant biomass was measured.

Enzyme activities: After 2 d of treatment for 28-d-old seedlings, enzymes were extracted according to Shan and Liang (2010). The activities of ascorbate peroxidase (APX, EC 1.11.1.11), glutathione reductase (GR, EC 1.6.4.2), monodehydroascorbate reductase (MDHAR, EC 1.6.5.4), and dehydroascorbate reductase (DHAR, EC 1.8.5.1) were measured according to Nakano and Asada (1981), Grace and Logan (1996), Miyake and Asada (1992), and Dalton et al. (1986), respectively. The specific activity for above enzymes was expressed as $\mathrm{U} \mathrm{mg}^{-1}$ (protein). One unit of APX activity was defined as the amount of APX catalyzing the oxidation of $1 \mu \mathrm{mol}$ (ascorbate) per min. One unit of GR activity was defined as the reduction of $1 \mu \mathrm{mol}(\mathrm{NADPH})$ per min. One unit of MDHAR activity was defined as the amount of enzyme that oxidizes $1 \mu \mathrm{mol}(\mathrm{NADH})$ per min. One unit of DHAR activity was defined as the amount of enzyme that produces $1 \mu \mathrm{mol}(\mathrm{As} A)$ per min. Protein concentration was measured according to Bradford (1976).

AsA/DHA ratio and the contents of $\mathrm{H}_{2} \mathrm{~S}$ and NO: After $2 \mathrm{~d}$ of treatment, AsA/DHA ratio was measured according to Hodges et al. (1996). The contents of $\mathrm{H}_{2} \mathrm{~S}$ and $\mathrm{NO}$ were measured according to Zhang et al. (2008) and Song et al. (2008), respectively. Above three indicators were determined by using TU-1810 UV-Vis spectrophotometer (Beijing Purkinje General Instrument Co., Ltd., China).

Chl and Car contents: After $2 \mathrm{~d}$ of treatment, the top fully expanded leaves were collected and immediately used to measure the contents of $\mathrm{Chl}$ and Car according 
to Lichtenthaler and Wellburn (1983). TU-1810 UV-Vis spectrophotometer (Beijing Purkinje General Instrument Co., Ltd., China) was used to measure $\mathrm{Chl}$ and Car contents.

Chl fluorescence and gas-exchange parameters: After 2 $\mathrm{d}$ of treatment, a Yaxin-1161G fluorometer (Yaxin, China) was used to measure $\mathrm{Chl}$ fluorescence parameters from 10:00 to $12: 00 \mathrm{~h}$. For dark adaptation, the leaves were covered for $30 \mathrm{~min}$. Then $\mathrm{F}_{\mathrm{v}} / \mathrm{F}_{\mathrm{m}}, \mathrm{q}_{\mathrm{P}}, \mathrm{q}_{\mathrm{N}}$, and $\Phi_{\mathrm{PSII}}$ were measured and calculated according to Dai and Shan (2019). Measurements were performed in a closed chamber under controlled growth conditions. Minimum fluorescence $\left(\mathrm{F}_{0}\right)$ was measured under a weak modulating radiation $[0.5$ $\mu$ mol(photon) $\mathrm{m}^{-2} \mathrm{~s}^{-1}$, and maximum fluorescence $\left(\mathrm{F}_{\mathrm{m}}\right)$ was induced by a saturating pulse of radiation $[2,400 \mu \mathrm{mol}$ (photon) $\mathrm{m}^{-2} \mathrm{~s}^{-1}$.

Gas-exchange parameters, such as $P_{\mathrm{N}}, E$, and $g_{\mathrm{s}}$ were measured by photosynthesis system (Licor-6400, USA) at an irradiance of $500 \mu \mathrm{mol}$ (photon) $\mathrm{m}^{-2} \mathrm{~s}^{-1}$ and a $\mathrm{CO}_{2}$ concentration of $400 \mu \mathrm{mol} \mathrm{mol}^{-1}$ from 10:00 to 12:00 h.

Plant biomass: After $7 \mathrm{~d}$ of treatment, fresh mass (FM) of plants under each treatment was recorded and then ovendried for $72 \mathrm{~h}$ at $80^{\circ} \mathrm{C}$. Dry mass (DM) of plants under each treatment was then recorded.

Leaf RWC: After $2 \mathrm{~d}$ of treatment, leaf RWC was determined according to Barrs and Weatherley (1962). RWC was calculated using the equation: $\mathrm{RWC}=[(\mathrm{FM}-\mathrm{DM}) /$ $(\mathrm{TM}-\mathrm{DM})] \times 100$, where FM, DM, and TM indicate fresh mass, dry mass, and saturated fresh mass, respectively.

Malondialdehyde (MDA) content and electrolyte leakage (EL): After $2 \mathrm{~d}$ of treatment, MDA content and EL were measured according to Han et al. (2014) and Anjum et al. (2015), respectively. MDA content was determined according to the thiobarbituric acid-reactive-substances assay by using $T U-1810 \mathrm{UV}-\mathrm{Vis}$ spectrophotometer
(Beijing Purkinje General Instrument Co., Ltd., China). For EL, leaf samples were incubated in $10 \mathrm{ml}$ of distilled water at $25^{\circ} \mathrm{C}$ for $6 \mathrm{~h}$ and then the electrical conductivity was recorded as EC1. Then samples were kept at $90^{\circ} \mathrm{C}$ for $2 \mathrm{~h}$ and the electrical conductivity was recorded as EC2. The electrical conductivity was measured by the conductivity meter (DDS-307, INESA Scientific Instrument Co., Ltd., China). EL was expressed as the percent of EC1 and EC2.

Statistical analysis: The data presented was the mean of five replicates. Means were compared by one-way analysis of variance (ANOVA) and Duncan's multiple range test at the 5\% level of significance. The program SAS 9.1 (SAS Institute, Cary, NC, USA) was used for the statistical analysis.

\section{Results}

$\mathbf{H}_{2} \mathbf{S}$ and NO: NaHS markedly increased the contents of $\mathrm{H}_{2} \mathrm{~S}$ and NO, compared with the control (Table 1). Pretreatment with $\mathrm{NaN}_{3}$ plus NaHS markedly decreased NO content, compared with NaHS alone. However, pretreatment with $\mathrm{NaN}_{3}$ plus NaHS had no obvious effect on $\mathrm{H}_{2} \mathrm{~S}$ content, compared with NaHS alone. Compared with $\mathrm{NaN}_{3}+\mathrm{NaHS}, \mathrm{NaN}_{3}+\mathrm{SNP}+\mathrm{NaHS}$ markedly increased NO content and had no obvious effect on $\mathrm{H}_{2} \mathrm{~S}$ content. Meanwhile, application of NaHS had no obvious effect on NO content in nial,nia2 mutant. The application of SNP+NaHS improved NO content in the leaves of nia1,nia2 mutant. These results indicated that NaHS induced NO production through NR.

AsA/DHA ratio and the activities of enzymes in AsA-GSH cycle: NaHS markedly increased AsA/DHA ratio and the activities of APX, GR, DHAR, and MDHAR, compared with the control (Tables 1,2). Pretreatment with $\mathrm{NaN}_{3}$ plus NaHS markedly inhibited the activities of above enzymes and reduced AsA/DHA ratio, compared with

Table 1. Effects of NaHS, $\mathrm{NaN}_{3}$, and SNP on AsA/DHA ratio and the contents of $\mathrm{H}_{2} \mathrm{~S}$ and NO in wild-type Arabidopsis and effects of NaHS and SNP on above indicators in Arabidopsis mutant nia1,nia2. Control - treatment of wild-type Arabidopsis with halfstrength Hoagland's solution; NaHS - treatment of wild-type Arabidopsis with $0.2 \mathrm{mM} \mathrm{NaHS}$; $\mathrm{NaN}_{3}+\mathrm{NaHS}_{-}$treatment of wild-type Arabidopsis with $0.1 \mathrm{mM} \mathrm{NaN}_{3}+0.2 \mathrm{mM} \mathrm{NaHS} \mathrm{NaN}_{3}+\mathrm{SNP}+\mathrm{NaHS}$ - treatment of wild-type Arabidopsis with $0.1 \mathrm{mM} \mathrm{NaN}_{3}+100 \mu \mathrm{M}$ $\mathrm{SNP}+0.2 \mathrm{mM}$ NaHS; nial, nia2 - treatment of Arabidopsis mutant nial, nia2 with half-strength Hoagland's solution; nial,nia2+NaHS - treatment of Arabidopsis mutant nial,nia2 with $0.2 \mathrm{mM} \mathrm{NaHS}$; nial,nia2+SNP+NaHS - treatment of Arabidopsis mutant nial,nia2 with $100 \mu \mathrm{M} \mathrm{SNP}+0.2 \mathrm{mM}$ NaHS. The plants were pretreated with half-strength Hoagland's solution or $\mathrm{NaN}_{3}$ for $8 \mathrm{~h}$ and then exposed to half-strength Hoagland's solution or NaHS or SNP+NaHS for $2 \mathrm{~d}$. Values represent mean \pm standard deviations (SD), different letters stand for significant difference between different treatments at $P<0.05$.

\begin{tabular}{llll}
\hline Treatment & $\mathrm{H}_{2} \mathrm{~S}\left[\mathrm{nmol} \mathrm{g}^{-1}(\mathrm{FM})\right]$ & $\mathrm{NO}\left[\mu \mathrm{mol} \mathrm{g}^{-1}\right.$ (protein) $]$ & AsA/DHA \\
\hline Control & $1.96 \pm 0.23^{\mathrm{b}}$ & $1.44 \pm 0.16^{\mathrm{b}}$ & $19.2 \pm 2.11^{\mathrm{b}}$ \\
$\mathrm{NaHS}$ & $2.72 \pm 0.35^{\mathrm{a}}$ & $1.90 \pm 0.23^{\mathrm{a}}$ & $22.0 \pm 2.65^{\mathrm{a}}$ \\
$\mathrm{NaN}_{3}+\mathrm{NaHS}$ & $2.65 \pm 0.30^{\mathrm{a}}$ & $1.13 \pm 0.14^{\mathrm{c}}$ & $16.8 \pm 1.93^{\mathrm{c}}$ \\
$\mathrm{NaN}_{3}+\mathrm{SNP}+\mathrm{NaHS}$ & $2.77 \pm 0.28^{\mathrm{a}}$ & $1.80 \pm 0.24^{\mathrm{a}}$ & $21.5 \pm 2.25^{\mathrm{a}}$ \\
nia1,nia2 & $2.06 \pm 0.25^{\mathrm{b}}$ & $1.16 \pm 0.12^{\mathrm{c}}$ & $17.0 \pm 1.92^{\mathrm{c}}$ \\
nial,nia2+NaHS & $2.60 \pm 0.29^{\mathrm{a}}$ & $1.22 \pm 0.15^{\mathrm{c}}$ & $17.4 \pm 1.87^{\mathrm{c}}$ \\
nia1,nia2+SNP+NaHS & $2.70 \pm 0.33^{\mathrm{a}}$ & $1.85 \pm 0.22^{\mathrm{a}}$ & $21.8 \pm 2.40^{\mathrm{a}}$ \\
\hline
\end{tabular}


Table 2. Effects of NaHS, $\mathrm{NaN}_{3}$, and SNP on the activities of enzymes in AsA-GSH cycle in wild-type Arabidopsis and effects of NaHS and SNP on above indicators in Arabidopsis mutant nia1,nia2. For explanation of treatments see Table 1. The plants were pretreated with half-strength Hoagland's solution or $\mathrm{NaN}_{3}$ for $8 \mathrm{~h}$ and then exposed to half-strength Hoagland's solution or $\mathrm{NaHS}$ or $\mathrm{SNP}+\mathrm{NaHS}$ for $2 \mathrm{~d}$. Values represent mean \pm standard deviations (SD), different letters stand for significant difference between different treatments at $P<0.05$.

\begin{tabular}{|c|c|c|c|c|}
\hline Treatment & $\mathrm{APX}\left[\mathrm{U} \mathrm{mg}^{-1}\right.$ (protein)] & GR [U mg ${ }^{-1}$ (protein)] & DHAR [U mg-1(protein)] & MDHAR [U mg-1(protein)] \\
\hline Control & $2.16 \pm 0.26^{\mathrm{b}}$ & $1.62 \pm 0.19^{b}$ & $1.16 \pm 0.16^{\mathrm{b}}$ & $0.92 \pm 0.11^{\mathrm{b}}$ \\
\hline NaHS & $2.55 \pm 0.24^{\mathrm{a}}$ & $1.97 \pm 0.26^{\mathrm{a}}$ & $1.55 \pm 0.18^{\mathrm{a}}$ & $1.16 \pm 0.14^{\mathrm{a}}$ \\
\hline $\mathrm{NaN}_{3}+\mathrm{NaHS}$ & $1.83 \pm 0.22^{\mathrm{c}}$ & $1.36 \pm 0.16^{\mathrm{c}}$ & $0.90 \pm 0.12^{\mathrm{c}}$ & $0.70 \pm 0.08^{c}$ \\
\hline $\mathrm{NaN}_{3}+\mathrm{SNP}+\mathrm{NaHS}$ & $2.65 \pm 0.30^{\mathrm{a}}$ & $1.90 \pm 0.22^{\mathrm{a}}$ & $1.61 \pm 0.22^{\mathrm{a}}$ & $1.22 \pm 0.17^{\mathrm{a}}$ \\
\hline nial,nia2 & $1.80 \pm 0.21^{\mathrm{c}}$ & $1.40 \pm 0.17^{\mathrm{c}}$ & $0.98 \pm 0.14^{c}$ & $0.74 \pm 0.09^{c}$ \\
\hline nia1,nia2+NaHS & $1.91 \pm 0.25^{\mathrm{c}}$ & $1.46 \pm 0.20^{\mathrm{c}}$ & $1.05 \pm 0.14^{\mathrm{c}}$ & $0.80 \pm 0.10^{\mathrm{c}}$ \\
\hline nia $1, n i a 2+\mathrm{SNP}+\mathrm{NaHS}$ & $2.60 \pm 0.29^{\mathrm{a}}$ & $1.86 \pm 0.22^{\mathrm{a}}$ & $1.55 \pm 0.20^{\mathrm{a}}$ & $1.15 \pm 0.16^{\mathrm{a}}$ \\
\hline
\end{tabular}

Table 3. Effects of NaHS, $\mathrm{NaN}_{3}$, and SNP on chlorophyll fluorescence parameters and photosynthetic pigments in wild-type Arabidopsis and effects of NaHS and SNP on above indicators in Arabidopsis mutant nia1,nia2. For explanation of treatments see Table 1. The plants were pretreated with half-strength Hoagland's solution or $\mathrm{NaN}_{3}$ for $8 \mathrm{~h}$ and then exposed to half-strength Hoagland's solution or NaHS or SNP + NaHS for $2 \mathrm{~d}$. Values represent mean \pm standard deviations (SD), different letters stand for significant difference between different treatments at $P<0.05$.

\begin{tabular}{lllllll}
\hline Treatment & Chl $\left[\mathrm{mg} \mathrm{g}^{-1}(\mathrm{FM})\right]$ & $\mathrm{Car}\left[\mathrm{mg} \mathrm{g}^{-1}(\mathrm{FM})\right]$ & $\mathrm{F}_{\mathrm{v}} / \mathrm{F}_{\mathrm{m}}$ & $\mathrm{q}_{\mathrm{P}}$ & $\mathrm{q}_{\mathrm{N}}$ & $\Phi_{\text {PSII }}$ \\
\hline Control & $2.02 \pm 0.25^{\mathrm{b}}$ & $0.47 \pm 0.07^{\mathrm{b}}$ & $0.69 \pm 0.08^{\mathrm{b}}$ & $0.73 \pm 0.09^{\mathrm{b}}$ & $0.37 \pm 0.05^{\mathrm{b}}$ & $0.41 \pm 0.05^{\mathrm{b}}$ \\
$\mathrm{NaHS}$ & $2.30 \pm 0.31^{\mathrm{a}}$ & $0.58 \pm 0.09^{\mathrm{a}}$ & $0.84 \pm 0.11^{\mathrm{a}}$ & $0.86 \pm 0.09^{\mathrm{a}}$ & $0.45 \pm 0.06^{\mathrm{a}}$ & $0.50 \pm 0.07^{\mathrm{a}}$ \\
$\mathrm{NaN}_{3}+\mathrm{NaHS}$ & $1.80 \pm 0.21^{\mathrm{c}}$ & $0.39 \pm 0.06^{\mathrm{c}}$ & $0.55 \pm 0.07^{\mathrm{c}}$ & $0.63 \pm 0.08^{\mathrm{c}}$ & $0.30 \pm 0.05^{\mathrm{c}}$ & $0.34 \pm 0.04^{\mathrm{c}}$ \\
$\mathrm{NaN}_{3}+\mathrm{SNP}+\mathrm{NaHS}$ & $2.23 \pm 0.26^{\mathrm{a}}$ & $0.54 \pm 0.07^{\mathrm{a}}$ & $0.80 \pm 0.09^{\mathrm{a}}$ & $0.86 \pm 012^{\mathrm{a}}$ & $0.40 \pm 0.07^{\mathrm{a}}$ & $0.49 \pm 0.06^{\mathrm{a}}$ \\
nial, nia2 $_{\text {nial, nia2+NaHS }}$ & $1.82 \pm 0.23^{\mathrm{c}}$ & $0.40 \pm 0.06^{\mathrm{c}}$ & $0.57 \pm 0.08^{\mathrm{c}}$ & $0.60 \pm 0.07^{\mathrm{c}}$ & $0.31 \pm 0.05^{\mathrm{c}}$ & $0.34 \pm 0.05^{\mathrm{c}}$ \\
nial,nia2+SNP+NaHS & $1.90 \pm 0.22^{\mathrm{bc}}$ & $0.43 \pm 0.06^{\mathrm{bc}}$ & $0.60 \pm 0.08^{\mathrm{c}}$ & $0.63 \pm 0.07^{\mathrm{c}}$ & $0.34 \pm 0.04^{\mathrm{bc}}$ & $0.37 \pm 0.05^{\mathrm{bc}}$ \\
\hline
\end{tabular}

Table 4. Effects of NaHS, NaN3 and SNP on water physiological indicators in wild-type Arabidopsis and effects of NaHS and SNP on above indicators in Arabidopsis mutant nial,nia2. For explanation of treatments see Table 1. The plants were pretreated with halfstrength Hoagland's solution or $\mathrm{NaN}_{3}$ for $8 \mathrm{~h}$ and then exposed to half-strength Hoagland's solution or NaHS or SNP $+\mathrm{NaHS}$ for $2 \mathrm{~d}$. Values represent mean \pm standard deviations (SD), different letters stand for significant difference between different treatments at $P<0.05$.

\begin{tabular}{lllll}
\hline Treatment & $E\left[\mathrm{mmol}\left(\mathrm{H}_{2} \mathrm{O}\right) \mathrm{m}^{-2} \mathrm{~s}^{-1}\right]$ & $g_{\mathrm{s}}\left[\mathrm{mmol}\left(\mathrm{H}_{2} \mathrm{O}\right) \mathrm{m}^{-2} \mathrm{~s}^{-1}\right]$ & $P_{\mathrm{N}}\left[\mu \mathrm{mol}\left(\mathrm{CO}_{2}\right) \mathrm{m}^{-2} \mathrm{~s}^{-1}\right]$ & $\mathrm{RWC}[\%]$ \\
\hline Control & $1.24 \pm 0.12^{\mathrm{b}}$ & $29.85 \pm 3.38^{\mathrm{b}}$ & $7.12 \pm 0.90^{\mathrm{b}}$ & $88.90 \pm 9.21^{\mathrm{ab}}$ \\
$\mathrm{NaHS}$ & $1.58 \pm 0.20^{\mathrm{a}}$ & $36.13 \pm 4.32^{\mathrm{a}}$ & $8.75 \pm 1.03^{\mathrm{a}}$ & $91.17 \pm 9.77^{\mathrm{a}}$ \\
$\mathrm{NaN}_{3}+\mathrm{NaHS}$ & $1.03 \pm 0.12^{\mathrm{c}}$ & $25.57 \pm 2.46^{\mathrm{c}}$ & $5.50 \pm 0.66^{\mathrm{c}}$ & $84.50 \pm 8.20^{\mathrm{b}}$ \\
$\mathrm{NaN}_{3}+\mathrm{SNP}+\mathrm{NaHS}$ & $1.50 \pm 0.20^{\mathrm{a}}$ & $34.77 \pm 4.15^{\mathrm{a}}$ & $8.36 \pm 0.77^{\mathrm{a}}$ & $90.10 \pm 8.88^{\mathrm{a}}$ \\
nial, nia2 $_{\text {nial, nia2+NaHS }}$ & $1.06 \pm 0.13^{\mathrm{c}}$ & $26.54 \pm 3.09^{\mathrm{c}}$ & $6.10 \pm 0.84^{\mathrm{c}}$ & $85.00 \pm 7.57^{\mathrm{b}}$ \\
nia1, nia2+SNP+NaHS & $1.10 \pm 0.11^{\mathrm{c}}$ & $27.10 \pm 3.22^{\mathrm{c}}$ & $6.34 \pm 0.73^{\mathrm{c}}$ & $85.30 \pm 9.04^{\mathrm{b}}$ \\
\hline
\end{tabular}

NaHS alone. Compared with $\mathrm{NaN}_{3}+\mathrm{NaHS}, \mathrm{NaN}_{3}+\mathrm{SNP}+$ NaHS significantly increased above indicators, which reversed the effects of $\mathrm{NaN}_{3}+\mathrm{NaHS}$. NaHS had no obvious effects on AsA/DHA ratio and the activities of above enzymes of AsA-GSH cycle in mutant nia1, nia2. However, application of SNP+NaHS improved above indicators in this mutant. These results indicated that signal molecule NO participated in the regulation of AsA-GSH cycle by NaHS through APX, GR, DHAR, and MDHAR, which further improved the AsA/DHA ratio.

Photosynthetic pigments and $\boldsymbol{P}_{\mathrm{N}}$ : NaHS markedly increased $P_{\mathrm{N}}$ and the contents of $\mathrm{Chl}$ and Car, compared with the control (Tables 3, 4). Pretreatment with $\mathrm{NaN}_{3}$ plus NaHS markedly reduced above parameters, compared with $\mathrm{NaHS}$ alone. Compared with $\mathrm{NaN}_{3}+\mathrm{NaHS}$, $\mathrm{NaN}_{3}+\mathrm{SNP}+\mathrm{NaHS}$ significantly increased above parameters, which reversed the effects of $\mathrm{NaN}_{3}+\mathrm{NaHS}$. 
Table 5. Effects of NaHS, $\mathrm{NaN}_{3}$, and SNP on MDA content, EL, plant biomass of wild-type Arabidopsis and effects of NaHS and SNP on above indicators in Arabidopsis mutant nia1,nia2. For explanation of treatments see Table 1. The plants were pretreated with half-strength Hoagland's solution or $\mathrm{NaN}_{3}$ for $8 \mathrm{~h}$ and then exposed to half-strength Hoagland's solution or NaHS or SNP $+\mathrm{NaHS}$ for $7 \mathrm{~d}$. MDA content and EL were measured after $2 \mathrm{~d}$ of treatment. Plant biomass was measured after $7 \mathrm{~d}$ of treatment. Values represent mean \pm standard deviations (SD), different letters stand for significant difference between different treatments at $P<0.05$.

\begin{tabular}{llll}
\hline Treatment & MDA $\left[\mathrm{nmol} \mathrm{g}{ }^{-1}(\mathrm{FM})\right]$ & EL $(\%)$ & Plant biomass [mg(FM) per plant $]$ \\
\hline Control & $4.8 \pm 0.52^{\mathrm{b}}$ & $7.7 \pm 0.81^{\mathrm{b}}$ & $81.0 \pm 7.36^{\mathrm{b}}$ \\
$\mathrm{NaHS}$ & $4.0 \pm 0.44^{\mathrm{c}}$ & $6.0 \pm 0.57^{\mathrm{c}}$ & $95.8 \pm 9.08^{\mathrm{a}}$ \\
$\mathrm{NaN}_{3}+\mathrm{NaHS}$ & $5.5 \pm 0.60^{\mathrm{a}}$ & $9.1 \pm 0.88^{\mathrm{a}}$ & $65.5 \pm 7.13^{\mathrm{c}}$ \\
$\mathrm{NaN}_{3}+\mathrm{SNP}+\mathrm{NaHS}$ & $4.2 \pm 0.39^{\mathrm{c}}$ & $6.3 \pm 0.70^{\mathrm{c}}$ & $93.6 \pm 9.75^{\mathrm{a}}$ \\
nia1,nia2 & $5.8 \pm 0.63^{\mathrm{a}}$ & $8.8 \pm 0.79^{\mathrm{a}}$ & $68.0 \pm 6.66^{\mathrm{c}}$ \\
nial,nia2+NaHS & $5.5 \pm 0.59^{\mathrm{a}}$ & $8.5 \pm 0.83^{\mathrm{a}}$ & $70.9 \pm 7.77^{\mathrm{c}}$ \\
nia1,nia2+SNP+NaHS & $4.3 \pm 0.50^{\mathrm{c}}$ & $6.5 \pm 0.65^{\mathrm{c}}$ & $94.4 \pm 8.59^{\mathrm{a}}$ \\
\hline
\end{tabular}

Application of NaHS had no effect on $P_{\mathrm{N}}$ and the contents of Chl and Car in mutant nial,nia2, whereas SNP+NaHS application improved these parameters. The present results indicated that signal molecule NO participated in the regulation of photosynthetic pigments and $P_{\mathrm{N}}$ by NaHS.

Chl fluorescence parameters: NaHS markedly increased Chl fluorescence parameters $\mathrm{F}_{\mathrm{v}} / \mathrm{F}_{\mathrm{m}}, \mathrm{q}_{\mathrm{P}}, \mathrm{q}_{\mathrm{N}}$, and $\Phi_{\mathrm{PSII}}$, compared with the control (Table 3). Pretreatment with $\mathrm{NaN}_{3}$ plus NaHS markedly reduced above parameters, compared with $\mathrm{NaHS}$ alone. Compared to $\mathrm{NaN}_{3}+\mathrm{NaHS}$, $\mathrm{NaN}_{3}+\mathrm{SNP}+\mathrm{NaHS}$ significantly increased Chl fluorescence parameters, which reversed the effects of $\mathrm{NaN}_{3}+\mathrm{NaHS}$. No obvious effects of NaHS application were found in nial, nia2 mutant, whereas SNP+NaHS improved its Chl fluorescence parameters. These results indicated that signal molecule NO is involved in the regulation of $\mathrm{Chl}$ fluorescence parameters by NaHS.

$\boldsymbol{E}, \boldsymbol{g}_{\text {s }}$ and RWC: NaHS markedly increased $E$ and $g_{\mathrm{s}}$, compared with the control (Table 4). Pretreatment with $\mathrm{NaN}_{3}$ plus NaHS markedly reduced above parameters, compared with $\mathrm{NaHS}$ alone. Compared with $\mathrm{NaN}_{3}+\mathrm{NaHS}$, $\mathrm{NaN}_{3}+\mathrm{SNP}+\mathrm{NaHS}$ significantly increased above indicators, which reversed the effects of $\mathrm{NaN}_{3}+\mathrm{NaHS}$. NaHS increased RWC, compared with the control (Table 4). However, there was no significant difference between $\mathrm{NaHS}$ and the control. Pretreatment with $\mathrm{NaN}_{3}$ plus NaHS markedly reduced RWC, compared with NaHS alone. Compared with $\mathrm{NaN}_{3}+\mathrm{NaHS}, \mathrm{NaN}_{3}+\mathrm{SNP}+\mathrm{NaHS}$ significantly increased RWC, which reversed the effects of $\mathrm{NaN}_{3}+\mathrm{NaHS}$. In nia1, nia2 mutant, NaHS application did not change $E$, $g_{\text {s }}$, and RWC, while SNP+NaHS improved these parameters. The present results indicated that signal molecule NO participated in the regulation of $E, g_{\mathrm{s}}$, and RWC by NaHS.

MDA, EL and plant biomass: NaHS markedly decreased MDA and EL, whereas notably increased plant biomass, compared with the control (Table 5). Pretreatment with $\mathrm{NaN}_{3}$ plus NaHS markedly increased MDA and EL and reduced plant biomass, compared with NaHS alone. Compared with $\mathrm{NaN}_{3}+\mathrm{NaHS}, \mathrm{NaN}_{3}+\mathrm{SNP}+\mathrm{NaHS}$ significantly decreased MDA and EL and increased plant biomass, which reversed the effects of $\mathrm{NaN}_{3}+\mathrm{NaHS}$. NaHS had no obvious effects on above indicators in mutant nia1,nia2. However, SNP+NaHS application improved these indicators in the mutant. The present results indicated that signal molecule NO participated in the regulation of MDA, EL, and plant growth by NaHS.

\section{Discussion}

Previous studies showed that exogenous $\mathrm{H}_{2} \mathrm{~S}$ had important effects on AsA-GSH cycle in plants, especially in stressed plants (Shan et al. 2011, Li et al. 2017, Kaya and Ashraf 2019). Our previous study showed that exogenous $\mathrm{H}_{2} \mathrm{~S}$ enhanced AsA-GSH cycle of wheat seedlings by regulating APX, GR, and DHAR (Shan et al. 2011). For Arabidopsis, our previous study showed that endogenous $\mathrm{H}_{2} \mathrm{~S}$ was involved in JA-regulated AsA-GSH cycle through APX, GR, DHAR, and MDHAR (Shan et al. 2018). In the present study, we found that exogenous $\mathrm{H}_{2} \mathrm{~S}$ enhanced AsA-GSH cycle through APX, GR, DHAR, and MDHAR in Arabidopsis leaves. Thus, our previous and present results clearly indicated that exogenous and endogenous $\mathrm{H}_{2} \mathrm{~S}$ had the same effects on AsA-GSH cycle in Arabidopsis. Many studies showed that the biological function of $\mathrm{H}_{2} \mathrm{~S}$ depended on its concentration (Shan et al. 2011). However, $\mathrm{H}_{2} \mathrm{~S}$ concentration in plants is usually very low under normal growth conditions, which cannot probably regulate physiological and biochemical processes and plant growth and development well. Applying exogenous $\mathrm{H}_{2} \mathrm{~S}$ can enhance $\mathrm{H}_{2} \mathrm{~S}$ amount in plants under normal growth conditions, which can further positively regulate physiological and biochemical processes, including plant growth and development. NO is another important gas signal molecule in plants (Batista et al. 2018, Hasanuzzaman et al. 2018, Okant and Kaya 2019). Ahmad et al. (2018) and our previous study showed that exogenous NO enhanced AsA-GSH cycle through APX, GR, DHAR, and MDHAR (Shan and Sun 2018, Shan et al. 2012). In the present study, our findings showed that endogenous and exogenous NO also had the same role in regulating AsA-GSH cycle. However, there is still no report about the role of NO in the regulation 
of AsA-GSH cycle by NaHS in plants. In this study, we found that NaHS induced NO production, which further enhanced AsA-GSH cycle in Arabidopsis. By this way, $\mathrm{NO}$ participated in the regulation of AsA/DHA ratio by NaHS in Arabidopsis. Therefore, our present findings demonstrated that gas signal molecule NO was involved in the regulation of AsA/DHA ratio by NaHS through AsAGSH cycle in Arabidopsis.

Plant growth has a close relationship with the photosynthesis. Moreover, $P_{\mathrm{N}}$ is closely related to contents of photosynthetic pigments. Parveen et al. (2017) showed that low concentration of NaHS improved the photosynthesis and the growth of submerged macrophytes. Duan et al. (2015) showed that suitable concentration of NaHS improved $P_{\mathrm{N}}$ and $\mathrm{Chl}$ contents of rice seedlings. In this study, our findings showed that NaHS also improved $P_{\mathrm{N}}$ and Chl content in Arabidopsis. Besides, we also found that NaHS enhanced Car content in Arabidopsis. Our present results clearly indicated that NaHS improved the photosynthesis by enhancing $P_{\mathrm{N}}$ and increasing the contents of photosynthetic pigments. Meanwhile, we found that gas signal molecule NO was involved in the regulation of the photosynthesis by NaHS in Arabidopsis.

The decreases in Chl fluorescence parameters, $F_{v} / F_{m}$ and $\Phi_{\text {PSII }}$, indicated that inhibition of photosynthesis and reduction of photochemical activity of PSII occurred. The higher $\mathrm{q}_{\mathrm{P}}$ implies higher PSII electron transfer activity. $\mathrm{q}_{\mathrm{N}}$ is indicative of a high photoprotective capacity for plants (Kumar and Prasad 2015). In this study, we found that NaHS significantly increased $\mathrm{F}_{\mathrm{v}} / \mathrm{F}_{\mathrm{m}}, \Phi_{\mathrm{PSII}}, \mathrm{q}_{\mathrm{P}}$, and $\mathrm{q}_{\mathrm{N}}$, which indicated that NaHS improved the electron transport, photochemical activity of PSII, and photoprotective capacity. Besides, we found that gas signal molecule NO was involved in the regulation of above Chl fluorescence parameters in Arabidopsis by NaHS. Combined with the results from the regulation of AsA-GSH cycle by NaHS, we deduced that NaHS improved PSII function by maintaining the redox status through AsA-GSH cycle.

The water status of plants, which was indicated by RWC, had important effects on the $E$ and $g_{\text {s. It has been }}$ documented that suitable concentration of NaHS markedly improved $E$ and $g_{\mathrm{s}}$ of rice seedlings (Duan et al. 2015). In this study, our findings showed that NaHS markedly improved leaf RWC of Arabidopsis. We also found that NaHS markedly improved $E$ and $g_{\mathrm{s}}$ in Arabidopsis, which was consistent with the results of Duan et al. (2015). Besides, we found that gas signal molecule NO was involved in the regulation of above water physiological parameters of Arabidopsis by NaHS.

Many studies showed that NaHS improved plant growth (Parveen et al. 2017, Chen et al. 2018). Chen et al. (2018) showed that NaHS ameliorated seed germination and seedling growth of cauliflower under lead stress. In this study, we also showed NaHS improved the growth of Arabidopsis. Meanwhile, our present study showed that NaHS markedly decreased MDA content and EL in Arabidopsis leaves. Besides, we found that gas signal molecule NO was involved in the regulation of above parameters of Arabidopsis by NaHS.

In this study, all the plants of different treatments were grown under normal water conditions. However, we found that there were significant differences in leaf RWC between different treatments, which indicated that different treatments had significant effects on the water conditions of Arabidopsis. Meanwhile, our results showed that there were significant differences in leaf MDA and EL between different treatments. So, our present results implied that the most fully expanded leaves of plants under some treatments were subjected to water stress. What is the reason for this result? Under the same normal water conditions, NaHS-treated plants had higher $E, g_{\mathrm{s}}$, and RWC than that of control plants. Thus, this difference may be due to the effects of NaHS on the water absorption and transport in plants. However, the physiological and molecular mechanisms of NaHS-regulated water absorption and transport of plants is still unclear. Therefore, it could be very interesting to investigate the effects of $\mathrm{NaHS}$ on water absorption and transport of plants, which could provide more information for the action mechanism of NaHS in regulating water regime of Arabidopsis.

\section{References}

Ahmad P., Ahanger M.A., Alyemeni M.N. et al.: Exogenous application of nitric oxide modulates osmolyte metabolism, antioxidants, enzymes of ascorbate-glutathione cycle and promotes growth under cadmium stress in tomato. Protoplasma 255: 79-93, 2018.

Anjum S., Tanveer M., Hussain S. et al.: Cadmium toxicity in maize (Zea mays L.): Consequences on antioxidative systems, reactive oxygen species and cadmium accumulation. Environ. Sci. Pollut. R. 22: 17022-17030, 2015.

Avashthi H., Pathak R.K., Pandey N. et al.: Transcriptome-wide identification of genes involved in ascorbate-glutathione cycle (Halliwell-Asada pathway) and related pathway for elucidating its role in antioxidative potential in finger millet (Eleusine coracana (L.)). - 3 Biotech 8: 499, 2018.

Barrs H.D., Weatherley P.E.: A re-examination of the relative turgidity techniques for estimating water deficits in leaves. Aust. J. Biol. Sci. 15: 413-428, 1962.

Batista P.F., Costa A.C., Müller C. et al.: Nitric oxide mitigates the effect of water deficit in Crambe abyssinica. - Plant Physiol. Bioch. 129: 310-322, 2018.

Bradford M.M.: A rapid and sensitive method for the quantitation of microgram quantities of protein utilizing the principle of protein-dye binding. - Anal. Biochem. 72: 248-254, 1976.

Chen Z., Yang B., Hao Z. et al:: Exogenous hydrogen sulfide ameliorates seed germination and seedling growth of cauliflower under lead stress and its antioxidant role. - J. Plant Growth Regul. 37: 5-15, 2018.

Dalton D.A., Russell S.A., Hanus F.J. et al.: Enzymatic reactions of ascorbate and glutathione that prevent peroxide damage in soybean root nodules. - P. Natl. Acad. Sci. USA 83: 38113815, 1986.

Duan B., Ma Y., Jiang M. et al.: Improvement of photosynthesis in rice (Oryza sativa L.) as a result of an increase in stomatal aperture and density by exogenous hydrogen sulfide treatment. - Plant Growth Regul. 75: 33-44, 2015.

Grace S.C., Logan B.A.: Acclimation of foliar antioxidant systems to growth irradiance in three broad-leaved evergreen species. - Plant Physiol. 112: 1631-1640, 1996.

Han S., Fang L., Ren X. et al.: MPK6 controls $\mathrm{H}_{2} \mathrm{O}_{2}$-induced root elongation by mediating $\mathrm{Ca}^{2+}$ influx across the plasma membrane of root cells in Arabidopsis seedlings. - New 
Phytol. 205: 695-706, 2014

Hao F., Zhao S., Dong H. et al.: Nia1 and Nia2 are involved in exogenous salicylic acid-induced nitric oxide generation and stomatal closure in Arabidopsis. - J. Integr. Plant Biol. 52: 298-307, 2010

Hasanuzzaman M., Oku H., Nahar K. et al.: Nitric oxide-induced salt stress tolerance in plants: ROS metabolism, signaling, and molecular interactions. - Plant Biotechnol. Rep. 12: 77-92, 2018.

Hodges D.M., Andrews C.J., Johnson D.A., Hamilton R.I.: Antioxidant compound responses to chilling stress in differentially sensitive inbred maize lines. - Physiol. Plantarum 98: 685-692, 1996.

Horemans N., Foyer C.H., Potters G., Asard H.: Ascorbate function and associated transport systems in plants. - Plant Physiol. Bioch. 38: 531-540, 2000.

Kaya C., Ashraf M.: The mechanism of hydrogen sulfide mitigation of iron deficiency-induced chlorosis in strawberry (Fragaria $\times$ ananassa) plants. - Protoplasma 256: 371-382, 2019.

Kiddle G., Pastori G.M., Bernard S. et al.: Effects of leaf ascorbate content on defense and photosynthesis gene expression in Arabidopsis thaliana. - Antioxid. Redox Sign. 5: 23-32, 2003.

Kumar A., Prasad M.N.V.: Lead-induced toxicity and interference in chlorophyll fluorescence in Talinum triangulare grown hydroponically. - Photosynthetica 53: 66-71, 2015.

Li H., Li M., Wei X. et al.: Transcriptome analysis of droughtresponsive genes regulated by hydrogen sulfide in wheat (Triticum aestivum L.) leaves. - Mol. Genet. Genomics 292: 1091-1110, 2017.

Lichtenthaler H.K., Wellburn A.L.: Determination of total carotenoids and chlorophylls $a$ and $b$ of leaf extracts in different solvents. - Biochem. Soc. T. 11: 591-593, 1983.

Mei Y., Zhao Y., Jin X. et al:: L-Cysteine desulfhydrasedependent hydrogen sulfide is required for methane-induced lateral root formation. - Plant Mol. Biol. 99: 283-298, 2019.

Miyake C., Asada K.: Thylakoid-bound ascorbate peroxidase in spinach chloroplasts and photoreduction of its primary oxidation product monodehydroascorbate radicals in thylakoids. - Plant Cell Physiol. 33: 541-553, 1992.

Nakano Y., Asada K.: Hydrogen peroxide is scavenged by ascorbate specific peroxidase in spinach chloroplasts. - Plant Cell Physiol. 22: 867-880, 1981.

Okant M., Kaya C.: The role of endogenous nitric oxide in melatonin-improved tolerance to lead toxicity in maize plants. - Environ. Sci. Pollut. R. 26: 11864-11874, 2019.

Parveen M., Asaeda T., Rashid M.H.: Hydrogen sulfide induced growth, photosynthesis and biochemical responses in three submerged macrophytes. - Flora 230: 1-11, 2017.
Potters G., De Gara L., Asard H., Horemans N.: Ascorbate and glutathione: guardians of the cell cycle, partners in crime? Plant Physiol. Bioch. 40: 537-548, 2002.

Recalde L., Vázquez A., Groppa M.D., Benavides M.P.: Reactive oxygen species and nitric oxide are involved in polyamineinduced growth inhibition in wheat plants. - Protoplasma 255: 1295-1307, 2018.

Shan C., Liang Z.: Jasmonic acid regulates ascorbate and glutathione metabolism in Agropyron cristatum leaves under water stress. - Plant Sci. 178: 130-139, 2010.

Shan C., He F., Xu G. et al.: Nitric oxide is involved in the regulation of ascorbate and glutathione metabolism in Agropyron cristatum leaves under water stress. - Biol. Plantarum 56: 187-191, 2012.

Shan C., Sun H.: Jasmonic acid-induced NO activates MEK1/2 in regulating the metabolism of ascorbate and glutathione in maize leaves. - Protoplasma 255: 977-983, 2018.

Shan C., Wang T., Zhou Y., Wang W.: Hydrogen sulfide is involved in the regulation of ascorbate and glutathione metabolism by jasmonic acid in Arabidopsis thaliana. - Biol. Plantarum 62: 188-193, 2018.

Shan C., Zhang S., Li D. et al.: Effects of exogenous hydrogen sulfide on the ascorbate and glutathione metabolism in wheat seedlings leaves under water stress. - Acta Physiol. Plant. 33: 2533-2540, 2011.

Shan C., Zhou Y., Liu M.: Nitric oxide participates in the regulation of the ascorbate-glutathione cycle by exogenous jasmonic acid in the leaves of wheat seedlings under drought stress. - Protoplasma 252: 1397-1405, 2015.

Song L.L., Ding W., Shen J. et al.: Nitric oxide mediates abscisic acid induced thermotolerance in the calluses from two ecotypes of reed under heat stress. - Plant Sci. 175: 826-832, 2008.

Sun L., Li Y., Miao W. et al.: NADK2 positively modulates abscisic acid-induced stomatal closure by affecting accumulation of $\mathrm{H}_{2} \mathrm{O}_{2}, \mathrm{Ca}^{2+}$ and nitric oxide in Arabidopsis guard cells. - Plant Sci. 262: 81-90, 2017.

Wang P., Du Y., Li Y. et al.: Hydrogen peroxide-mediated activation of MAP kinase 6 modulates nitric oxide biosynthesis and signal transduction in Arabidopsis. - Plant Cell 22: 2981-2998, 2010.

Zhang H., Hu L.Y., Hu K.D. et al.: Hydrogen sulfide promotes wheat seed germination and alleviates the oxidative damage against copper stress. - J. Integr. Plant Biol. 50: 1518-1529, 2008.

Zhao X., Zhao X.W., He H. et al.: Mechanisms of extracellular $\mathrm{NO}$ and $\mathrm{Ca}^{2+}$ regulating the growth of wheat seedling roots. J. Plant Biol. 53: 275-281, 2010.

(C) The authors. This is an open access article distributed under the terms of the Creative Commons BY-NC-ND Licence. 